\title{
Employee Satisfaction in Online Reviews
}

\author{
Philipp Koncar ${ }^{(凶)}$ and Denis Helic \\ Graz University of Technology, Graz, Austria \\ \{philipp.koncar, dhelic\}@tugraz.at
}

\begin{abstract}
Employee satisfaction impacts the efficiency of businesses as well as the lives of employees spending substantial amounts of their time at work. As such, employee satisfaction attracts a lot of attention from researchers. In particular, a lot of effort has been previously devoted to the question of how to positively influence employee satisfaction, for example, through granting benefits. In this paper, we start by empirically exploring a novel dataset comprising two million online employer reviews. Notably, we focus on the analysis of the influencing factors for employee satisfaction. In addition, we leverage our empirical insights to predict employee satisfaction and to assess the predictive strengths of individual factors. We train multiple prediction models and achieve accurate prediction performance (ROC AUC of best model $=0.89$ ). We find that the number of benefits received and employment status of reviewers are most predictive, while employee position has less predictive strengths for employee satisfaction. Our work complements existing studies and sheds light on the influencing factors for employee satisfaction expressed in online employer reviews. Employers may use these insights, for example, to correct for biases when assessing their reviews.
\end{abstract}

Keywords: Employee satisfaction · Employer reviews $\cdot$ Kununu

\section{Introduction}

Employee satisfaction contributes to better employee engagement [56,60] and is strongly connected to the overall performance and productivity of businesses [32]. Further, employee satisfaction impacts the lives of many employees as they spend substantial amounts of their time at work [20,22]. Hence, employee satisfaction has attracted much attention in existing research $[1,2,4,10,35,40,54]$. While some studies considered the advantage of high employee satisfaction for businesses (e.g., increased performance, reduced employee turnover or absences) [49, $50,55]$, other studies focused on how to increase and foster employee satisfaction (e.g., through changing positions or granting benefits) $[12,51]$. Here, we set our focus on the latter and extend existing research by conducting a large-scale analysis of online employer reviews contained in an unexplored dataset. The potential of such reviews to complement traditional management measurements has been depicted in previous research [11,21,45], allowing to overcome problems with traditional assessment methods (e.g., annual employee surveys), such

(C) The Author(s) 2020

S. Aref et al. (Eds.): SocInfo 2020, LNCS 12467, pp. 152-167, 2020.

https://doi.org/10.1007/978-3-030-60975-7_12 
as employees that are reticent about feedback out of fear for consequences [46] or managers not open for criticism [29].

Research Question. Based on findings in previous research, in this paper we ask how employee benefits $[1,15,48,57]$, employee positions $[10,13,14,18]$ as well as employment status $[5,23,25]$ interact with employee satisfaction expressed in online employer reviews.

Approach. To answer our research question, we empirically analyze online employer reviews found on kununu, a so far unexplored reviewing platform where employees can anonymously rate their employers. In particular, we adhere to existing research $[1,5,10,13-15,18,23,25,48,57]$ and set our focus on the influence of employee benefits, position, and employment status on employee satisfaction. Our dataset comprises more than 2200000 reviews of more than 380000 employers operating in 43 different industries. On kununu, reviews comprise an overall rating ranging between one ("very bad") and five ("very good") stars as well as additional details, such as the position of reviewers and the benefits they had received. We interpret these overall ratings as an expression of employee satisfaction. Finally, we conduct a logistic regression to predict employee satisfaction, allowing us to assess the predictive strength of individual influencing factors.

Findings and Contributions. Overall, our results empirically confirm previous findings in existing research. For example, we observe that higher numbers of employee benefits positively influence employee satisfaction expressed in online employer reviews $[1,15,48,57]$. Further, we find that former employees review more negatively as compared to current employees, which reflects previous results suggesting that dissatisfaction causes employees to quit $[5,23,25]$. However, we also find that employees of higher positions (e.g., managers) review more positively, suggesting that employee position may have an influence on employee satisfaction, contradicting previous findings stating the opposite [10,18]. Lastly, with our prediction experiment, we find that the number of benefits granted to and the employment status of employees have the highest predictive strengths for employee satisfaction. When we combine all individual features, we achieve a mean ROC AUC of 0.89 .

Our work contributes to the understanding of the influencing factors for employee satisfaction expressed in online employer reviews. Thus, we add fruitful input to the debate of employee satisfaction in social and management sciences.

\section{Related Work}

Employee Satisfaction. Employee satisfaction has been interpreted in a number of ways in previous research. For example, Blood [4] stated that employee satisfaction is depending on the values one brings to the job. On the contrary, Schneider and Schmitt [54] defined it as entirely depending on organizational conditions and not on predispositions of employees. Locke [35] thought of it 
more as an interaction between work conditions and individual employees and stressed that satisfaction is relevant to the engagement of the latter. More precisely, he defined employee satisfaction as a positive or pleasant emotional state resulting from people's appreciations of their own job.

Previous studies focused on the positive influence of high employee satisfaction on commitment and engagement of employees. For example, researchers investigated the positive relationship of employee satisfaction and engagement of hotel managers [24] or teachers [40]. Other works studied the positive influence of employee satisfaction on turnover [2] or on organizational commitment [36].

On the contrary to these studies, we analyze employee satisfaction as a dependent variable (i.e., aspects such as pay or rewards that benefit employee satisfaction). Existing studies demonstrated, for example, how to effectively reward employees for increased employee satisfaction $[1,12,57]$ or how employee position influences employee satisfaction $[10,18]$. We base our work on these previous studies to analyze a novel dataset of more than two million online employer reviews, allowing us to find new insights regarding the influencing factors of employee satisfaction expressed in online reviews.

Online Reviews. Numerous works have studied online employer reviews and most works focused on the reviewing platform glassdoor ${ }^{1}$. For example, Marinescu et al. [41] described a selection bias in online reviews, meaning that people with extreme opinions are more motivated to share their experiences as compared to people with moderate opinions. Chandra [6] depicted differences in work-life balance between eastern and western countries using reviews written on glassdoor. Luo [37] inferred important characteristics impacting employee satisfaction and named innovation and quality as one of the most important. In a more recent work, Green et al. [21] analyzed employer reviews on glassdoor and their influence on stock returns. Their results indicate that companies with improvements in reviews (i.e., reviews becoming more positive over time) significantly outperform companies with declines (i.e., reviews becoming more negative over time). Dabirian et al. [11] extracted 38,000 reviews of highest and lowest ranked employers on glassdoor in order to identify what employees care about. Contrary to these works, we investigate online employer reviews found on kununu and also consider a larger quantity of reviews.

Online reviews have also been studied extensively in other contexts. As early as in 2001, Chatterjee [7] studied how negative online reviews influence consumers. Chen et al. [9] investigated online reviews of automobiles and depicted that the intention to write reviews is depending on the price and quality of products. Li and Hitt [34] as well as Chen et al. [8] studied online book reviews, where the former found that the average rating declines over time and the latter found that recommendations in reviews can have a positive impact on sales. Other works focused on the impact of online reviews on hotel business performance [59,61]. More recent and established works investigated the helpfulness of online reviews mostly written on Amazon [17,31,38,39], but also on

\footnotetext{
${ }^{1}$ https://glassdoor.com.
} 
the video games platform Steam [3,19] or the review aggregation website Metacritic $[30,53]$. Our work separates from these studies, which analyze reviews of material goods, as we focus on reviews of work experiences.

\section{Dataset and Empirical Results}

\subsection{Dataset}

We conduct our analysis on a novel dataset comprising reviews found on kununu, a platform that offers employees the possibility to anonymously review their employer. The platform is provided in English as well as in German for employers located in Austria, Germany, Switzerland (all since 2007) and the USA (since 2013). Reviews written on kununu consist of 13 individual aspect ratings, such as company culture or teamwork, each ranging between 1 ("very bad") and 5 ("very good"). These aspect ratings are aggregated into an overall rating for each review. Additionally, reviews contain a headline (120 characters at a maximum) and information about the job status of a reviewer (i.e, whether they are a current or former employee). The position of employees (i.e., either "employee", "management", "temporary", "freelancer/self-employed", "co-op", "apprentice" or "other"), the benefits and perks (e.g., life insurance or free parking) as well as free-form text are optionally disclosed by reviewers.

We automatically crawled ${ }^{2}$ all reviews present on kununu up to the end of September 2019. Since kununu is bilingual, we had to normalize German names

Table 1. Dataset statistics. The table lists descriptive statistics of our preprocessed dataset comprising employer reviews written on kununu up to the end of September 2019.

\begin{tabular}{l|l}
\hline \# Industries & 43 \\
\# Employers & 385736 \\
\# Reviews & 2240276 \\
.. \# thereof for Austria (since 2007) & 139760 \\
.. \# thereof for Germany (since 2007) & 1255641 \\
.. \# thereof for Switzerland (since 2007) & 114514 \\
.. \# thereof for USA (since 2013) & 730361 \\
.. \# thereof including positions & 2239189 \\
.. \# thereof including perks or benefits & 1855491 \\
\hline Overall rating median & 3.85 \\
Review length (in words) median & 24 \\
\# Benefits median & 5 \\
\hline
\end{tabular}

${ }^{2}$ We used multiprocessing and multiple web proxies to shorten the execution time of the crawling and implemented other measures (e.g., testing for missing or duplicate data) as well as manually checked a selection of reviews to assure data integrity. 


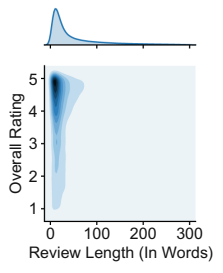

Austria

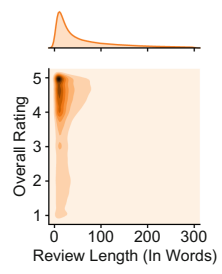

Germany

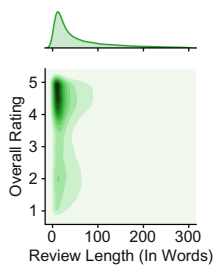

Switzerland

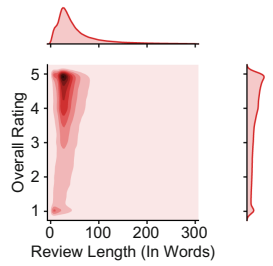

USA

Fig. 1. Review length and overall ratings. The figure depicts bivariate KDEs of review length in words (distributions truncated at 300 words which is still above the $95^{\text {th }}$ percentile for all languages) and overall ratings of reviews. We observe that most of the reviews contain none or only a few words as well as weak negative correlations between the two, suggesting that dissatisfied employees rather devote time and effort to write optional text.

(e.g., of positions) to English ones in order to compare reviews across languages. We list descriptive statistics of our preprocessed dataset, comprising 2240276 reviews of 385736 employers operating in 43 different industries, in Table 1.

Preliminary Descriptive Analysis. We observe a larger number of reviews with positive overall ratings as compared to reviews with negative overall ratings (overall rating median $=3.85$ ). Most notably, reviews of employers located in the USA seem to be more controversial with slightly higher probabilities for one star ratings as compared to European countries. We report a slight increase in the mean overall rating over time for the three European countries, whereas this mean for the USA decreases during the first years only to catch up with other countries in 2017. Regarding the length (in words) of optional review texts, we report long-tailed distributions for each of the four countries, indicating that the majority of reviews contains none or only a few words, whereas only a small number of reviews contain longer texts (review length median $=24$ ). To see if reviews with optional texts are rather positive or negative, we compute Spearman's rank correlation coefficients between the number of characters in reviews with optional text and their respective overall ratings for each of the four countries. We depict bivariate kernel density estimations (KDE) between these two in Fig. 1. Here, we find a weak negative correlation (all $p$-values $<0.0005$ ) for each European country with $\rho$ ranging between -0.20 and -0.17 . In case of reviews of employers located in the USA, the negative correlation is much weaker with $\rho=-0.08$ ( $p$-value $<0.0005)$. This suggests that dissatisfied employees may rather invest time to address issues as compared to satisfied employees.

Overall, we report cultural, temporal and textual differences across reviews and an in-depth analysis of these differences might be promising for future work. 


\subsection{Empirical Results}

Next we study the relationship between employee satisfaction and employee benefits, employee position as well as employment status.

Employee Benefits. To investigate the influence of benefits on employee satisfaction, we compute Spearman's rank correlation coefficients between the number of benefits received and the overall rating of reviews, respectively for each of the four countries in our dataset.

We depict bivariate KDEs of the number of benefits and overall ratings of reviews in Fig. 2. Overall, we observe a positive correlation between the number of benefits received and overall ratings for each of the four countries. This suggests that the more benefits employees receive, the higher is their overall rating in their reviews. However, strength of correlation varies across countries. While the mean Spearman's rank correlation coefficient for European countries is 0.46 (all $p$-values $<0.0005$ ), this correlation is smaller for reviews of employers located in the USA with $\rho=0.29$ ( $p$-value $<0.0005)$, despite the fact that USA reviews have, on average, the second largest number of benefits per review (Austria: 6.32, Germany: 5.59, Switzerland: 5.38, USA: 6.30). Hence, we observe cultural differences, indicating that benefits for employees working for companies in the USA are not as influential as for employees of European companies.

Our findings on the positive influence of employee benefits for employee satisfaction are similar to those in existing research [57]. Further, studies reported that benefits become more important as part of the compensation of employees [15] and have grown in relevance to employees as well as in their variety [48]. Also, not all benefits positively correlate with satisfaction to the same extent and some of them even negatively correlate with each other [1]. Thus, we analyze what benefits were granted most to satisfied employees (reviews with overall rating $\geq 4$ ) and compare that to benefits granted to dissatisfied employees (reviews with overall rating $\leq 2$ ) in order to infer if benefits are equally relevant.

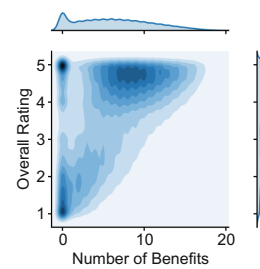

Austria

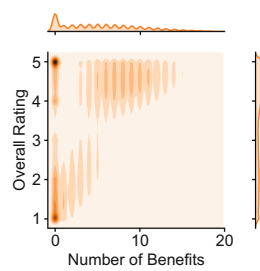

Germany

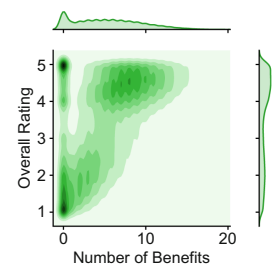

Switzerland

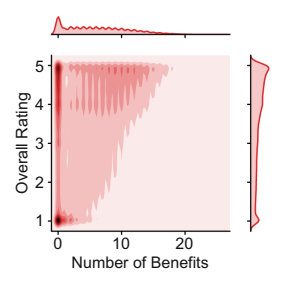

USA

Fig. 2. Influence of benefits on employee satisfaction. We plot bivariate KDEs of the number of benefits and overall ratings of reviews, respectively for each country. Overall, we observe positive correlations between the two for all countries, with the exception of the USA for which we find weaker correlations. This observation supports previous findings $[1,15,48,57]$ and indicates the positive influence of employee benefits on employee satisfaction. 


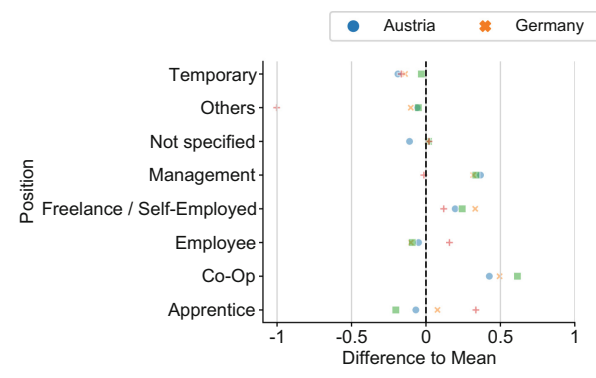

Difference to Overall Ratings

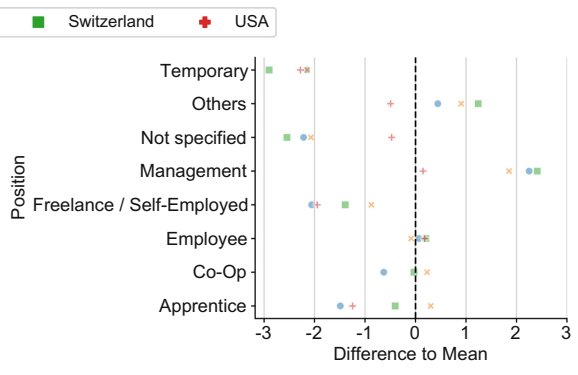

Difference to Number of Benefits

Fig. 3. Influence of position on employee satisfaction. In this figure we illustrate how employee position influences employee satisfaction in online employer reviews. In Figure a, we depict differences in overall ratings compared to country means, respectively for each position (note that we have no co-ops in the USA based version of kununu). Overall, we observe that, contrary to our expectations, employee positions have influence on overall ratings. For example, managers give a higher overall rating compared to the mean overall rating in all European countries. In Figure b, we depict differences in the number of benefits received compared to country means, respectively for each position. Again, we observe that benefits depend on position. For example, managers get, on average, two additional benefits compared to the country mean.

Here, we observe that satisfied employees receive different benefits as compared to dissatisfied employees. In particular, satisfied employees receive benefits, such as flexible working hours, $401 k$ or fitness programs, that have a high impact on work and life quality. On the contrary, dissatisfied employees receive benefits, such as parking or discounts. Hence, online employer reviews reflect similar behavior as reported in previous research [1].

Employee Position. We study the influence of employee positions on employee satisfaction by computing for each position and country the difference to the respective country mean of overall ratings. We assess the significance of mean differences by checking for overlaps of $95 \%$ bootstrap confidence intervals.

In Fig. 3, we depict the results of our analysis on employee positions. Mean differences are significant in all cases, with the exception of reviews without a position specified ("Not specified") for all four countries, other positions ("Others") for European countries, normal employees and apprentices in Austria, temporaries in Germany and Switzerland as well as managers in the USA. Specifically, we observe that co-ops (i.e., working students) have most positive reviews across all European countries (our dataset contains no reviews of co-ops for the USA), rating significantly more positive compared to the respective country mean (about half a star; 0.50 in numbers). Managers rate second most highest in Austria, Germany and Switzerland (all three significant), whereas managers in the USA rate slightly more negative compared to the country mean 


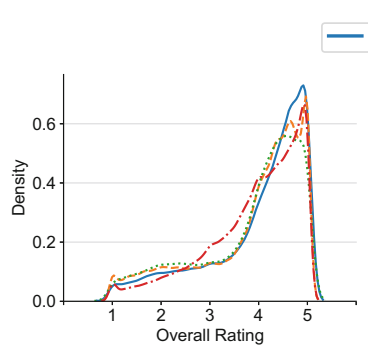

Current Employees

_ Austria - - Germany \#... Switzerland - . USA

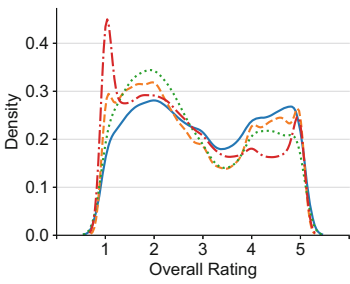

Former Employees

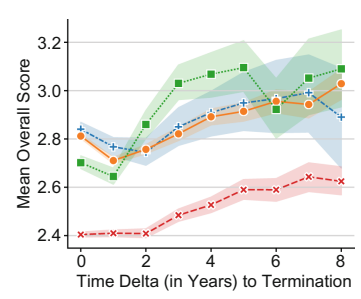

Time Since Termination

Fig. 4. Influence of employment satisfaction on employment status. The figure illustrates how employee satisfaction potentially influences employment status. We plot KDEs of overall ratings for current (a) and former (b) employees, indicating that current employees have higher probabilities for positive overall ratings as compared to former employees who have higher probabilities to review more negatively. Further, we depict the time (in years) that lies between writing a review and termination of former employees (with $95 \%$ bootstrap confidence intervals), suggesting that overall ratings increase with time passed.

(non-significant). Apprentices rate significantly higher in the USA compared to European Countries, suggesting that interns and trainees are more satisfied with their education and instruction in the USA.

Our findings contradict existing research which suggests that employee position does not significantly influence employee satisfaction [10,18]. Additionally, existing studies showed that higher positions (e.g., managers) often receive more compensation $[13,14]$. To investigate whether this behavior is reflected in online employer reviews, we compare the number of benefits granted to employee positions to the respective country means. Again, we assess significance of mean differences by checking for overlaps of $95 \%$ bootstrap confidence intervals.

We depict results for the influence of position on the number of benefits received in Fig. 3b. Differences are significant in all cases, except for normal employees in all four countries, co-ops in Germany and Switzerland as well as managers in the USA. We observe that managers in German speaking countries, on average, receive two benefits more compared to the respective country means. This behavior is different to managers in the USA, who, on average and according to our dataset, receive the same number of benefits as the country mean and perhaps suggesting higher levels of equality among different employee positions in the USA. Unsurprisingly, temporary and self-employed personnel receive fewer benefits in all four countries as they are not permanently employed.

Overall, our findings contradict existing results $[10,18]$ that suggest no influence of position on employee satisfaction. However, we confirm existing studies suggesting that higher positions receive more compensation $[13,14]$. 
Employment Status. We analyze the potential impact of employee satisfaction on employment status by computing two-sample Kolmogorov-Smirnov tests between overall rating distributions of current and former employees, respectively for each country. Further, we investigate the impact of time lying between creations of reviews and terminations of former employees (up to 8 years as data becomes sparse with longer time periods).

We illustrate the results for this analysis in Fig. 4. In general, current employees rate rather positively, having a mean overall rating of 3.86 across all countries, whereas possible frustration of former employees is clearly reflected in their mean overall rating of 2.81 . We depict the distribution of overall ratings for current and for former employees in Fig. 4a and in Fig. 4b respectively. In any case, distributions are significantly different (all $p$-values $<0.0005$ ) according to the two-sample Kolmogorov-Smirnov tests. For European countries, probabilities are similar for either negative or positive reviews, while probabilities for one star reviews are much higher for reviews of employers in the USA, suggesting higher frustration levels for their employees after termination as compared to employees of European companies.

Our findings reflect reports in existing research which suggest that employee satisfaction is the main reason for staying with or leaving an employer [25]. Further, employee satisfaction is strongly, positively correlated with organization commitment [5] and employee dissatisfaction is antecedent to forming an intention to quit [23], providing a potential explanation for our findings.

In Fig. 4c, we depict mean overall ratings according to the time that lies between the terminations of former employees and the creations of their reviews, respectively for each country. Our results suggest that the longer a termination lies in the past, the more positive are the reviews. While the mean overall rating of reviews written one month after termination is 2.59 , this value is 3.91 after ten months, and mean values increase even more with longer time deltas.

Overall, our findings support our initial expectation that former employees review more negatively as compared to current employees. This effect, however, seems to weaken with more time lying between the termination of former employees and creation of their reviews.

\section{Predicting Employee Satisfaction}

We conduct a logistic regression to predict employee satisfaction based on our empirical results. We distinguish between reviews from satisfied and dissatisfied employees based on the overall rating contained in reviews. More precisely, we consider reviews with overall ratings less than or equal to the first quartile (overall rating $\leq 2.42$ ) as expressions of dissatisfaction and reviews with overall ratings equal to or greater than the third quartile (overall rating $\geq 4.54$ ) as expressions of satisfaction. We create classes this way to counteract the general bias towards more positive reviews (cf. Table 1 for the overall rating median). 
We implement our logistic regression with default parameters ${ }^{3}$ and train multiple models respectively with the following feature $\operatorname{spaces}^{4}$ :

(i) Country: The country the reviewed employer is located in.

(ii) Year: The year the review was written in.

(iii) Review Length: The length of reviews defined by the number of words.

(iv) Benefits: The number of benefits the reviewing employee received.

(v) Position: The position of the reviewing employee.

(vi) Employment Status: The employment status of the reviewing employee.

(vii) All: The combination of all the above feature spaces.

Note that we use one-hot encoding to transform categorical features (country, year, position and employment status) and that we standardize numerical features (review length and benefits). Further, we remove all reviews that are missing any of the described features. This leaves us with 430998 positive and 419309 negative reviews. To evaluate and compare performance of our models, we use ten-fold cross validation and report mean ROC AUC values over the folds.

Results. In Fig. 5 we illustrate the mean ROC AUC respectively for each feature space. When we consider individual feature spaces, the number of benefits is most

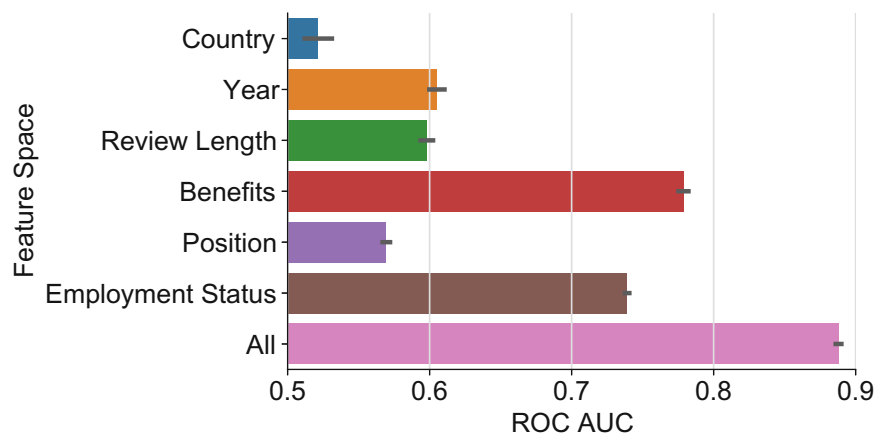

Fig. 5. Prediction results. In this figure we depict the results of our prediction experiment with which we assess the predictive strength of individual feature spaces and the combination of those for the prediction of employee satisfaction. The error bars indicate $95 \%$ bootstrap confidence intervals. We observe that the number of benefits received and the employment status of employees have the highest predictive strengths, while other feature spaces perform only minimally better than the random baseline (ROC AUC of 0.5). The combination of all features further improves the performance to a mean ROC AUC of 0.89 , demonstrating that we can accurately predict employee satisfaction and that the consideration of all features is reasonable.

\footnotetext{
${ }^{3}$ As implemented in scikit-learn 0.22.2 (https://scikit-learn.org/0.22/).

${ }^{4}$ We do not consider the time delta between termination of employees and creation of their reviews as this feature is only available for $14 \%$ of reviews in our dataset.
} 
predictive for employee satisfaction with a mean ROC AUC of 0.78 , followed by the employment status with a value of 0.74 . Our remaining feature spaces perform notably worse. The model we train with the year the review was written results in a mean ROC AUC of 0.61, similar to the model using the length of reviews which results in a value of 0.60 . We report that the position of employees has very low predictive power with a mean ROC AUC of 0.57 , only followed by the country the reviewed employer is located in, which performed the worst with 0.52 and only minimally better than a random baseline (0.5). However, when we combine all the individual feature spaces, we can further increase performance by 0.11 (compared to the model trained on the number of benefits) to 0.89 , indicating that the features provide complementary information on employee satisfaction.

\section{Discussion}

With our empirical analysis of online employer reviews we provide new insights into the influencing factors for employee satisfaction expressed in such reviews. Our prediction experiment demonstrates the predictive strengths of individual features for predicting employee satisfaction. In the following, we discuss our findings and connect our results to our initial research question.

Support For Existing Studies in Online Employer Reviews. Overall, we find support for findings in previous studies [1,5,13-15,23, 25,48,57]. One exception are our findings on positions, suggesting that, contrary to previous works $[10,18]$, employee positions influence employee satisfaction. In particular, we observed higher employee satisfaction for managers. One possible explanation for this observation could be that managers review more positively in order to increase the reputation of their company (under the assumption that they are currently employed at respective companies). To test for this, we compute mean overall ratings for current and former managers. Here, we find a mean overall rating of 4.12 for current managers $(n=193872)$ and 2.72 for former managers $(n=72258)$, suggesting support for our assumption.

We observed that benefits have less impact on overall ratings for reviews of employers located in the USA as compared to European countries. After further investigating this result, we notice that USA based reviews include fewer benefits related to work-life balance (e.g., flexible workhours or home office allowed) as compared to German speaking countries. Thus, one possible explanation for the weaker correlation could be the lack of work-life benefits, which according to existing research are important for high employee satisfaction $[47,58]$.

In the case of the influence of employee positions on overall ratings, we found that managers of European companies are more satisfied as compared to managers of companies located in the USA. This observation can be a reflection of different leadership styles between the USA and European countries, where for the former pressure on managers might be higher because decision making is much more egalitarian in the USA compared to European countries [44]. However, this could also be due to the fact that managers in German speaking 
countries enjoy more advantages as compared to those working for companies located in the USA (cf Fig. 3b). Also notable is that freelancers rate more positive in all four countries compared to respective country means, supporting exiting work indicating that freelancers are more satisfied with their job because of higher levels of freedom $[16,42,52]$.

We found that former employees rate more positive the more time lies between the creation of reviews and their termination. This suggests that frustration of reviewers dissipates over time ("time heals wounds"), which follows the intuition that forgiving becomes easier over time [43]. However, we suggest a more detailed analysis of this observation for future work.

Prediction. Finally, our prediction experiment revealed that the number of benefits and the position of employees are most predictive for employee satisfaction. However, only when considering the combination of all features, we achieved the best prediction performance. Note that more sophisticated approaches, such as deep learning, might further improve the prediction performance. Based on our observations, we suggest that employers should assign more responsibilities to their employees as well as grant them more freedom, especially related to worklife balance. Overall, these observations are strongly related to long existing theories of management sciences, such as Herzberg's Two-Factor Theory [26-28] which is based on similar suggestions.

Limitations. We based our work on employer reviews found on kununu, only one platform among many others providing similar reviewing possibilities. Despite the large amount and the variety of data, the quality of our analysis may be improved by considering additional platforms, such as glassdoor.com. However, note that our analysis requires adjustments to other platforms as they use different rating mechanics and consider other employer characteristics. Thus, our analysis is biased towards the particularities of kununu. Further, we acknowledge a potential bias introduced by reviewers, such as different interpretations of rating scales or herding behavior, as suggested by existing research [33]. We leave an in-depth analysis of this phenomenon on kununu for future work. For our prediction experiment, we defined employee satisfaction based on the quartiles of overall rating distributions. While small adjustments to this definition did not noticeably alter our results, other definition may result in different findings.

\section{Conclusion}

In this paper, we investigated online employer reviews comprised in an unexplored dataset to shed light on the influencing factors for employee satisfaction. We obtain comparable results from online employer reviews to results from existing research based on e.g., survey data. The only exception to this are our results regarding the influence of employee position on employee satisfaction where we find that they are more important in online reviews as compared to previous findings. Further, we observe cultural differences across employers, for example, benefits have less impact on employee satisfaction in the USA as compared to 
European countries. With our prediction experiment we depicted the predictive strengths of our individual findings, suggesting that the number of benefits and the employment status convey the most information for predicting employee satisfaction. When we combined all different features, we achieved a mean ROC AUC of 0.89 , demonstrating the we can accurately predict satisfied and dissatisfied employees based on only a handful of features. Employers may use our findings to correct for biases when assessing their reviews or adapt management measures, such as shifting parts of compensation towards more benefits, as we demonstrated that they are most influential for employee satisfaction in reviews.

For future work, we plan to extend our analysis to learn more about the reviewing behavior of employees, for example, by considering the individual review aspects or by investigating industrial differences. Further, we want to adapt our analysis methods to other datasets comprising online employer reviews.

Acknowledgments. Parts of this work were funded by the go!digital Next Generation programme of the Austrian Academy of Sciences.

\section{References}

1. Artz, B.: Fringe benefits and job satisfaction. Int. J. Manpower (2010)

2. Aydogdu, S., Asikgil, B.: An empirical study of the relationship among job satisfaction, organizational commitment and turnover intention. Int. Rev. Manage. Mark. 1(3), 43 (2011)

3. Barbosa, J.L., Moura, R.S., Santos, R.L.d.S.: Predicting Portuguese steam review helpfulness using artificial neural networks. In: Proceedings of the 22nd Brazilian Symposium on Multimedia and the Web, pp. 287-293. ACM (2016)

4. Blood, M.R.: Work values and job satisfaction. J. Appl. Psychol. 53(6), 456 (1969)

5. Brown, S.P., Peterson, R.A.: Antecedents and consequences of salesperson job satisfaction: meta-analysis and assessment of causal effects. J. Mark. Res. 30(1), 63-77 (1993)

6. Chandra, V.: Work-life balance: eastern and western perspectives. Int. J. Hum. Resour. Manage. 23(5), 1040-1056 (2012)

7. Chatterjee, P.: Online reviews: do consumers use them? (2001)

8. Chen, P.Y., Wu, S.y., Yoon, J.: The impact of online recommendations and consumer feedback on sales. In: ICIS 2004 Proceedings, p. 58 (2004)

9. Chen, Y., Fay, S., Wang, Q.: Marketing implications of online consumer product reviews. Bus. Week 7150, 1-36 (2003)

10. Cornelißen, T.: The interaction of job satisfaction, job search, and job changes. An empirical investigation with German panel data. J. Happiness Stud. 10(3), 367-384 (2009)

11. Dabirian, A., Kietzmann, J., Diba, H.: A great place to work!? Understanding crowdsourced employer branding. Bus. Horiz. 60(2), 197-205 (2017)

12. Darling, K., Arn, J., Gatlin, R.: How to effectively reward employees. Ind. Managem.-Chicago Atlanta- 39, 1-4 (1997)

13. De Cremer, D.: How self-conception may lead to inequality: effect of hierarchical roles on the equality rule in organizational resource-sharing tasks. Group Organ. Manage. 28(2), 282-302 (2003) 
14. De Cremer, D., van Dijk, E., Folmer, C.R.: Why leaders feel entitled to take more. Psychol. Perspect. Ethical Behav. Decis. Making 107-119 (2009)

15. DeCenzo, D.A., Robbins, S.P., Verhulst, S.L.: Fundamentals of Human Resource Management. Wiley, Hoboken (2016)

16. Deprez, A., Raeymaeckers, K.: A longitudinal study of job satisfaction among flemish professional journalists. J. Mass Commun. 2(1), 1-15 (2012)

17. Diaz, G.O., Ng, V.: Modeling and prediction of online product review helpfulness: a survey. In: Proceedings of the 56th Annual Meeting of the Association for Computational Linguistics (Volume 1: Long Papers), pp. 698-708 (2018)

18. Dienhart, J.R., Gregoire, M.B.: Job satisfaction, job involvement, job security, and customer focus of quick-service restaurant employees. Hospit. Res. J. 16(2), 29-43 (1993)

19. Eberhard, L., Kasper, P., Koncar, P., Gütl, C.: Investigating helpfulness of video game reviews on the steam platform. In: 2018 Fifth International Conference on Social Networks Analysis, Management and Security (SNAMS), pp. 43-50. IEEE (2018)

20. Ernst Kossek, E., Ozeki, C.: Work-family conflict, policies, and the job-life satisfaction relationship: a review and directions for organizational behavior-human resources research. J. Appl. Psychol. 83(2), 139 (1998)

21. Green, T.C., Huang, R., Wen, Q., Zhou, D.: Crowdsourced employer reviews and stock returns. J. Financ. Econ. 134, 236-251 (2019)

22. Greenhaus, J.H., Beutell, N.J.: Sources of conflict between work and family roles. Acad. Manag. Rev. 10(1), 76-88 (1985)

23. Griffeth, R.W., Hom, P.W., Gaertner, S.: A meta-analysis of antecedents and correlates of employee turnover: update, moderator tests, and research implications for the next millennium. J. Manag. 26(3), 463-488 (2000)

24. Gunlu, E., Aksarayli, M., Perçin, N.Ş.: Job satisfaction and organizational commitment of hotel managers in Turkey. Int. J. Contemp. Hospit. Manage. (2010)

25. Hausknecht, J.P., Rodda, J., Howard, M.J.: Targeted employee retention: performance-based and job-related differences in reported reasons for staying. Hum. Resour. Manage.: Publ. Cooper. School Bus. Adm. Univ. Michigan Alliance Soc. Hum. Resour. Manage. 48(2), 269-288 (2009)

26. Herzberg, F.: Motivation to Work. Routledge, Abingdon (2017)

27. Herzberg, F., Mausner, B., Snyderman, B.: The motivation to work (1959)

28. Herzberg, F.I.: Work and the nature of man (1966)

29. Holland, P., Cooper, B.K., Hecker, R.: Use of social media at work: a new form of employee voice? Int. J. Hum. Resour. Manage. 27(21), 2621-2634 (2016)

30. Kasper, P., Koncar, P., Santos, T., Gütl, C.: On the role of score, genre and text in helpfulness of video game reviews on metacritic. In: 2019 Sixth International Conference on Social Networks Analysis, Management and Security (SNAMS), p. todo. IEEE (2019)

31. Kim, S.M., Pantel, P., Chklovski, T., Pennacchiotti, M.: Automatically assessing review helpfulness. In: Proceedings of the 2006 Conference on Empirical Methods in Natural Language Processing, pp. 423-430. Association for Computational Linguistics (2006)

32. Kumar, V., Pansari, A.: Measuring the benefits of employee engagement. MIT Sloan Manage. Rev. 56(4), 67 (2015)

33. Lauw, H.W., Lim, E.P., Wang, K.: Quality and leniency in online collaborative rating systems. ACM Trans. Web (TWEB) 6(1), 1-27 (2012)

34. Li, X., Hitt, L.M.: Self-selection and information role of online product reviews. Inf. Syst. Res. 19(4), 456-474 (2008) 
35. Locke, E.A.: The nature and causes of job satisfaction. Handb. Ind. Organ. Psychol. (1976)

36. Lumley, E., Coetzee, M., Tladinyane, R., Ferreira, N.: Exploring the job satisfaction and organisational commitment of employees in the information technology environment. Southern Afr. Bus. Rev. 15(1) (2011)

37. Luo, N., Zhou, Y., Shon, J.: Employee satisfaction and corporate performance: mining employee reviews on glassdoor.com (2016)

38. Malik, M., Iqbal, K.: Review helpfulness as a function of linguistic indicators. Int. J. Comput. Sci. Netw. Secur. 18, 234-240 (2018)

39. Malik, M., Hussain, A.: An analysis of review content and reviewer variables that contribute to review helpfulness. Inf. Process. Manage. 54(1), 88-104 (2018)

40. Malik, M.E., Nawab, S., Naeem, B., Danish, R.Q.: Job satisfaction and organizational commitment of university teachers in public sector of Pakistan. Int. J. Bus. Manage. 5(6), 17 (2010)

41. Marinescu, I., Klein, N., Chamberlain, A., Smart, M.: Incentives can reduce bias in online reviews. Technical report, National Bureau of Economic Research (2018)

42. Massey, B.L., Elmore, C.J.: Happier working for themselves? Job satisfaction and women freelance journalists. J. Pract. 5(6), 672-686 (2011)

43. McCullough, M.E., Fincham, F.D., Tsang, J.A.: Forgiveness, forbearance, and time: the temporal unfolding of transgression-related interpersonal motivations. J. Pers. Soc. Psychol. 84(3), 540 (2003)

44. Meyer, E.: Being the boss in Brussels, Boston, and Beijing. Harv. Bus. Rev. 95, 70-77 (2018)

45. Miles, S.J., Mangold, W.G.: Employee voice: untapped resource or social media time bomb? Bus. Horiz. 57(3), 401-411 (2014)

46. Milliken, F.J., Morrison, E.W., Hewlin, P.F.: An exploratory study of employee silence: Issues that employees don't communicate upward and why. J. Manage. Stud. 40(6), 1453-1476 (2003)

47. Muse, L., Harris, S.G., Giles, W.F., Feild, H.S.: Work-life benefits and positive organizational behavior: is there a connection? J. Organ. Behav.: Int. J. Ind. Occup. Organ. Psychol. Behav. 29(2), 171-192 (2008)

48. Newman, J.M., Gerhart, B., Milkovich, G.T.: Compensation. McGraw-Hill Higher Education, New York (2016)

49. Podsakoff, P.M., Williams, L.J.: The relationship between job performance and job satisfaction. Generalizing Lab. Field Sett. 207, 253 (1986)

50. Ramayah, T., Nasurdin, A.: Integrating importance into the relationship between job satisfaction and commitment: a conceptual model. ICFAI J. Organ. Behav. 5(2), 20-27 (2006)

51. Rathi, N., Rastogi, R.: Job satisfaction and psychological well-being. Icfai Univ. J. Organ. Behav. 7(4), 47-57 (2008)

52. Ryan, K.M.: The performative journalist: job satisfaction, temporary workers and american television news. Journalism 10(5), 647-664 (2009)

53. Santos, T., Lemmerich, F., Strohmaier, M., Helic, D.: What's in a review: discrepancies between expert and amateur reviews of video games on metacritic. In: Proceedings of the ACM on Human-Computer Interaction, vol. 3, no. CSCW, p. 140 (2019)

54. Schneider, B., Schmitt, N.: Staffing Organizations. Goodyear Publishing Company (1976)

55. Smith, P.C., et al.: The measurement of satisfaction in work and retirement: a strategy for the study of attitudes (1969) 
56. Steinhaus, C.S., Perry, J.L.: Organizational commitment: does sector matter? Public Product. Manage. Rev. 278-288 (1996)

57. Tessema, M.T., Ready, K.J., Embaye, A.B.: The effects of employee recognition, pay, and benefits on job satisfaction: cross country evidence. J. Bus. Econ. 4(1), $1-12(2013)$

58. Thompson, C.A., Beauvais, L.L., Lyness, K.S.: When work-family benefits are not enough: the influence of work-family culture on benefit utilization, organizational attachment, and work-family conflict. J. Vocat. Behav. 54(3), 392-415 (1999)

59. Vermeulen, I.E., Seegers, D.: Tried and tested: the impact of online hotel reviews on consumer consideration. Tour. Manag. 30(1), 123-127 (2009)

60. Weiss, H.M.: Deconstructing job satisfaction: separating evaluations, beliefs and affective experiences. Hum. Resour. Manage. Rev. 12(2), 173-194 (2002)

61. Ye, Q., Law, R., Gu, B.: The impact of online user reviews on hotel room sales. Int. J. Hospit. Manage. 28(1), 180-182 (2009)

Open Access This chapter is licensed under the terms of the Creative Commons Attribution 4.0 International License (http://creativecommons.org/licenses/by/4.0/), which permits use, sharing, adaptation, distribution and reproduction in any medium or format, as long as you give appropriate credit to the original author(s) and the source, provide a link to the Creative Commons license and indicate if changes were made.

The images or other third party material in this chapter are included in the chapter's Creative Commons license, unless indicated otherwise in a credit line to the material. If material is not included in the chapter's Creative Commons license and your intended use is not permitted by statutory regulation or exceeds the permitted use, you will need to obtain permission directly from the copyright holder. 